Military Technical College Kobry El-Kobbah, Cairo, Egypt

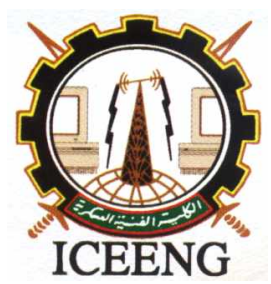

\section{$6^{\text {th }}$ International Conference on Electrical Engineering ICEENG 2008}

\title{
Modeling load uncertainties in reactive power compensation of distribution feeders using interval arithmetic
}

\author{
By \\ M. Abouelsaad * M. El Bahy * N. Abdel-Gawad* M. Abou El-Ata * I. El Shair**
}

\section{Abstract:}

Integrating uncertainties of the load demands and those associated with capacitor allocation in radial distribution feeders is the aim of the present paper. Modeling of the uncertainties accompanying the load parameters is important in relation to the problem of reactive power compensation in distribution systems using capacitors allocation. Interval mathematics provides a powerful tool for modeling uncertainties. The uncertainties related to load demand are modeled by solving the load flow using a developed interval backward/ forward sweep technique. The interval voltage outcomes are used in the governing equations of the capacitor allocation analysis. Interval distribution functions defining the real power losses and the voltage sensitivity are introduced to, sequentially, order the sensitive nodes that require compensation. A heuristic technique is formulated to determine the interval capacitor size, interval maximum cost saving, and the corresponding interval loss reduction. A significant improvement in the voltage profile is achieved using the proposed technique. Implementation of the technique is demonstrated using two realistic radial distribution feeders.

\section{Keywords:}

Reactive power compensation, distribution systems, interval mathematics, uncertainty.

* Shoubra Faculty of Engineering, Benha University, Egypt

** Ain Shams University, Abbassia, Cairo, Egypt 


\section{Introduction:}

Energy management through reactive power compensation on distribution systems has, recently, emerged as a topic of current research interest [1-4]. Reactive power flow in a distribution system produces losses and results in increased rating for the system components. Shunt capacitors are usually installed to reduce these power losses, increase the released thermal capacities of the lines and transformers and improve the system voltage profile.

In a distribution system, the reactive load is always varying and it is not a realistic proposition to determine capacitor sizes and locations based on an average of the reactive loads as even this numbers subject to change as the load varies [5]. Also this load demand is subject to different types of errors, such as the measured or calculated errors in the lines and transformers parameters in the system, and the assumed power demand errors at different busses [6-9]. So, in reality, these input parameters are quite uncertain. In addition, many of the reactive power compensation techniques involve the optimization of a cost function which requires parameters such as the cost of the capacitors, the cost of energy and the cost of the peak power savings to which only an estimation; i.e. single-point, without exact certainty can be obtained [5]. Consequently, the validity of the generated results is questionable.

According to the above, these uncertainties can be classified into two categories. The first is related to the load demands while the other is associated with the data employed in the capacitor allocation analysis, which is usually derived from many sources with varying degrees of accuracy.

Uncertainties can be looked upon as a condition in which the possibility of errors exists as a result of having less than total information about the surrounding environment. They are beyond the utility's foreknowledge or control.

Modeling the uncertainties in the load demand can be based on two general approaches. The first is a probabilistic approach where probability distributions for all of the uncertainties are assumed. The second approach is called "Unknown but bounded" in which upper and lower limits on the uncertainties are assumed without probability distributions [10].

The first approach has been used in solving load flow [11-13]. Interval mathematics provides a tool for the practical implementation and extension of the second approach (Unknown but bounded) concept. There is no need for many simulation runs because the total variation in the output is known given the total variation in input parameters. Interval mathematics has been recently used in load flow studies to account for load uncertainties [6-9]. The idea of an interval approach is particularly interesting, if one considers the possibility of finding all the solutions within a domain. This advantage is especially important given the non-linearity of the problem give rise to at least one feasible solution which may lead to an undesirable blackout after the system collapse 
[14].

In this paper, a new method is proposed to integrate all the above uncertainties to produce a realistic solution for capacitor allocation in distribution systems. The uncertainties related to load demand are modeled by solving the load flow using an interval backward/ forward sweep technique. This technique in the interval analysis is more suitable for radial distribution feeders' analysis. The interval backward/forward power flow technique is faster in convergence, and produces sharp bounds in the voltage outcomes. The resulting interval voltage outcomes are used in the governing equations of the capacitor allocation analysis. Interval distribution functions defining the real power losses and the voltage sensitivity are introduced to order the sensitive nodes which require reactive compensation. Once locations are identified, the standard capacitor size, at a selected location, is determined through the optimization of the cost saving function, then the interval maximum cost saving and the corresponding interval loss reduction are determined. Successful implementation of the proposed technique is demonstrated for two practical feeders.

\section{Interval mathematics}

Interval mathematics provides a useful tool in determining the effects of uncertainty in parameters used in a computation. In this form of mathematics, interval numbers are used instead of ordinary single point numbers. An interval number is defined as an ordered pair of real numbers representing the lower and upper bounds of the parameter range [10]. An interval number can then be formally defined as follows; [a, b], where a $\leq \mathrm{b}$. In the special case where the upper and lower bounds of an interval number are equal, the interval is referred to as a point or a degenerate interval and interval mathematics is reduced to ordinary single point arithmetic.

Given two interval numbers, $[\mathrm{a}, \mathrm{b}]$ and $[\mathrm{c}, \mathrm{d}]$, the rules for interval addition, subtraction, multiplication, and division are as follows:

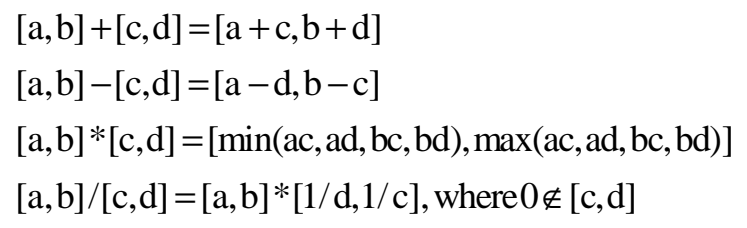

Implementing interval analysis techniques confronts some obstacles because its algebraic structure is unlike that of common single point arithmetic. Accordingly, interval computations may produce wide bounds.

Interval of complex numbers may be of two types, rectangular complex interval and circular complex interval [15]. A rectangular complex interval is defined by two real intervals $\mathrm{x}$ and $\mathrm{y}[15]$, 
$z=x+i y=\{x+i y: x \in x, y \in y\}$

and produces a rectangle of complex numbers in the complex plane. Complex interval operations are defined in terms of the real intervals $x \in$ and $y \in$ in the same way that complex operations on $\mathrm{z}=\mathrm{x}+\mathrm{i} \mathrm{y}$ are defined in terms of $\mathrm{x}$ and $\mathrm{y}$. If $\mathrm{x}_{1}=\left[\mathrm{a}_{1}, \mathrm{~b}_{1}\right], \mathrm{y} 1=$ $\left[\mathrm{c}_{1}, \mathrm{~d}_{1}\right], \mathrm{x}_{2}=\left[\mathrm{a}_{2}, \mathrm{~b}_{2}\right]$, and $\mathrm{y}_{2}=\left[\mathrm{c}_{2}, \mathrm{~d}_{2}\right]$. Let $\mathrm{Z}_{1}=\mathrm{x}_{1}+\mathrm{i} \mathrm{y}_{1}$ and $\mathrm{Z}_{2}=\mathrm{x}_{2}+\mathrm{i} \mathrm{y}_{2}$, then $[6,15]$

$\mathrm{Z}_{1} \pm \mathrm{Z}_{2}=\left(\mathrm{x}_{1} \pm \mathrm{x}_{2}\right)+\mathrm{i}\left(\mathrm{y}_{1} \pm \mathrm{y}_{2}\right)$

$\mathrm{Z}_{1} \times \mathrm{Z}_{2}=\left(\mathrm{x}_{1} \mathrm{x}_{2}-\mathrm{y}_{1} \mathrm{y}_{2}\right)+\mathrm{i}\left(\mathrm{x}_{1} \mathrm{y}_{2} \pm \mathrm{x}_{2} \mathrm{y}_{1}\right)$

$\mathrm{Z}_{1} / \mathrm{Z}_{2}=\frac{\left(\mathrm{x}_{1} \mathrm{x}_{2}+\mathrm{y}_{1} \mathrm{y}_{2}\right)}{\mathrm{x}_{2}^{2}+\mathrm{y}_{2}^{2}}+\mathrm{i} \frac{\left(\mathrm{x}_{2} \mathrm{y}_{1}-\mathrm{x}_{1} \mathrm{y}_{2}\right)}{\mathrm{x}_{2}^{2}+\mathrm{y}_{2}^{2}}$

A problem with multiplication of rectangular complex intervals is that $\mathrm{x}_{1} \mathrm{x}_{2^{-}}$ $\mathrm{y}_{1} \mathrm{y}_{2}+\mathrm{i}\left(\mathrm{x}_{1} \mathrm{y}_{2}+\mathrm{x}_{2} \mathrm{y}_{1}\right)$ produces a rectangle in the complex plane [15], whereas the actual range is not this shape. Therefore, an overestimation of the exact range of $Z_{1} Z_{2}$ may occur. The circular complex interval used in the present work eliminates this difficulty.

\section{Interval Backward Forward Sweep load flow Technique}

The algorithm for the backward/forward sweep power flow simulation for three-phase radial distribution system is straightforward [16] as it is based on the two main laws in electrical engineering, the Kirchoff's current and voltage laws. It is specially formulated for the power flow of a distribution system which is commonly radial configuration.

The algorithm steps can be summarized as follows [16]:

The voltage at the root node is assumed to be known and a flat voltage profile, equal to the voltage of the root node, has been assumed for the initial voltages at the other nodes. Hence in per unit system, the voltage at the root node and the initial voltages at the other nodes is assumed to be $1+\mathrm{j} 0$ p.u.

At iteration $\mathrm{k}$, the iterative methodology involves three steps;

1. Current injection calculation for each node

$\left[\begin{array}{l}\mathrm{I}_{\mathrm{ia}} \\ \mathrm{I}_{\mathrm{ib}} \\ \mathrm{I}_{\mathrm{ic}}\end{array}\right]^{(\mathrm{k})}=\left[\begin{array}{l}\left(\mathrm{S}_{\mathrm{ia}} / \mathrm{V}_{\mathrm{ia}}{ }^{(k-1)}\right)^{*} \\ \left(\mathrm{~S}_{\mathrm{ib}} / \mathrm{V}_{\mathrm{ib}}{ }^{(k-1)}\right)^{*} \\ \left(\mathrm{~S}_{\mathrm{ic}} / \mathrm{V}_{\mathrm{ic}}{ }^{\left({ }^{k}-1\right)}\right)^{*}\end{array}\right]-\left[\begin{array}{lll}\mathrm{Y}_{\mathrm{ia}}{ }^{*} & & \\ & \mathrm{Y}_{\mathrm{ib}}{ }^{*} & \\ & & \mathrm{Y}_{\mathrm{ic}}{ }^{*}\end{array}\right]\left[\begin{array}{l}\mathrm{V}_{\mathrm{ia}} \\ \mathrm{V}_{\mathrm{ib}} \\ \mathrm{V}_{\mathrm{ic}}\end{array}\right]^{(\mathrm{k}-1)}$

where:

$\mathrm{I}_{\mathrm{ia}}, \mathrm{I}_{\mathrm{ib}}, \mathrm{I}_{\mathrm{ic}}$ : are current injections at node $\mathrm{i}$ corresponding to constant power load and shunt elements

$\mathrm{S}_{\mathrm{ia}}, \mathrm{S}_{\mathrm{ib}}, \mathrm{S}_{\mathrm{ic}}$ : are scheduled (known) power injections at node $\mathrm{i}$

$\mathrm{V}_{\mathrm{ia}}, \mathrm{V}_{\mathrm{ib}}, \mathrm{V}_{\mathrm{ic}}$ : are voltages at node $\mathrm{i}$ 
$\mathrm{Y}_{\mathrm{ia}}, \mathrm{Y}_{\mathrm{ib}}, \mathrm{Y}_{\mathrm{ic}}$ : are admittances of all shunt elements at node $\mathrm{i}$

2. Backward sweep to sum up branch current: starting from the branch in the last layer and moving towards the root node. The current in line section 1 is computed as

$$
\left[\begin{array}{l}
\mathrm{J}_{\mathrm{la}} \\
\mathrm{J}_{\mathrm{bb}} \\
\mathrm{J}_{\mathrm{lc}}
\end{array}\right]^{(\mathrm{k})}=-\left[\begin{array}{l}
\mathrm{I}_{\mathrm{ja}} \\
\mathrm{I}_{\mathrm{jb}} \\
\mathrm{I}_{\mathrm{jc}}
\end{array}\right]^{(\mathrm{k})}+\sum_{\mathrm{m} \in \mathrm{M}}\left[\begin{array}{l}
\mathrm{J}_{\mathrm{ma}} \\
\mathrm{J}_{\mathrm{mb}} \\
\mathrm{J}_{\mathrm{mc}}
\end{array}\right]^{(\mathrm{k})}
$$

where:

$\mathrm{J}_{\mathrm{la}}, \mathrm{J}_{\mathrm{lb}}, \mathrm{J}_{\mathrm{lc}}$ : are the current flows on branch 1

$\mathrm{M}$ : is the set of branches connected to node $\mathrm{j}$

3. Forward sweep to update nodal voltage: starting from the first layer and moving towards the last layer. The voltage at node $\mathrm{j}$ is

$$
\left[\begin{array}{c}
\mathrm{V}_{\mathrm{ja}} \\
\mathrm{V}_{\mathrm{jb}} \\
\mathrm{V}_{\mathrm{jc}}
\end{array}\right]^{(\mathrm{k})}=\left[\begin{array}{c}
\mathrm{V}_{\mathrm{ia}} \\
\mathrm{V}_{\mathrm{ib}} \\
\mathrm{V}_{\mathrm{ic}}
\end{array}\right]^{(\mathrm{k})}-\mathrm{Z}_{1}\left[\begin{array}{c}
\mathrm{J}_{\mathrm{la}} \\
\mathrm{J}_{\mathrm{lb}} \\
\mathrm{J}_{\mathrm{lc}}
\end{array}\right]^{(\mathrm{k})}
$$

where,

$Z_{1}$ : is the series impedance of line section, 1 , and is represented by a $3 \times 3$ matrix:

$$
Z_{1}=\left[\begin{array}{ccc}
Z_{a a, 1} & Z_{a b, 1} & Z_{a c, 1} \\
Z_{b a, 1} & Z_{b b, 1} & Z_{b c, 1} \\
Z_{c a, 1} & Z_{c b, 1} & Z_{c c, 1}
\end{array}\right]
$$

After these three steps are executed in one iteration, the voltage mismatches at each node for all phase are calculated:

$$
\begin{aligned}
& \Delta \mathrm{V}_{\mathrm{ia}}{ }^{(\mathrm{k})}=\mathrm{V}_{\mathrm{ia}}{ }^{(\mathrm{k})}-\mathrm{V}_{\mathrm{ia}}{ }^{(\mathrm{k}-1)} \\
& \Delta \mathrm{V}_{\mathrm{ib}}{ }^{(\mathrm{k})}=\mathrm{V}_{\mathrm{ib}}{ }^{(\mathrm{k})}-\mathrm{V}_{\mathrm{ib}}{ }^{(\mathrm{k}-1)} \\
& \Delta \mathrm{V}_{\mathrm{ic}}{ }^{(\mathrm{k})}=\mathrm{V}_{\mathrm{ic}}{ }^{\left({ }^{(}\right)}-\mathrm{V}_{\mathrm{ic}}{ }^{(\mathrm{k}-1)}
\end{aligned}
$$

If the real or imaginary part of any of these voltage mismatches is greater than a prespecified convergence criterion, steps 1,2 and 3 are repeated until convergence is achieved.

However, to account for the uncertainty of the load demands, the real and reactive loads have been treated as interval numbers rather than fixed numbers and consequently, the above complex arithmetic has been replaced by complex interval arithmetic in this section. 


\section{Interval distribution functions for the bus voltage and power loss}

Many researchers have attempted using fuzzy set theory to solve capacitor placement problem [17]. They used fuzzy set theory to solve the optimal capacitor allocation problem. They defined membership functions for the real power losses and the voltage sensitivity. The proposed method relies on using both heuristic and interval distribution functions to identify suitable sensitive nodes for capacitor placement. This eliminates the need to use any analytical or iterative numerical programming method to search for the optimal capacitor locations [17].

The interval functions that define the bus voltage and the power loss are as follows:

$$
\begin{aligned}
& \mathrm{f}_{\mathrm{v}}(\mathrm{i})=\frac{1}{1+\left[\frac{\mathrm{V}_{\mathrm{i}}-1}{\mathrm{~V}_{\text {max }}-\mathrm{V}_{\text {min }}}\right]^{2}} \\
& \mathrm{f}_{\mathrm{p}}(\mathrm{i})=1-\frac{\mathrm{P}_{\text {loss }}(\mathrm{i})}{\mathrm{C}_{\mathrm{p}}} \quad \mathrm{i}=1,2, \ldots, \mathrm{n} \quad \mathrm{P}_{\text {loss }} \leq \mathrm{C}_{\mathrm{p}} \\
& \mathrm{f}_{\mathrm{p}}(\mathrm{i})=0 \quad \mathrm{i}=1,2, \ldots, \mathrm{n} \quad \mathrm{P}_{\text {loss }} \geq \mathrm{C}_{\mathrm{p}}
\end{aligned}
$$

Where:

$\mathrm{V}_{\mathrm{i}}=$ interval bus i pu voltage

$\mathrm{V}_{\max }=$ maximum voltage limit

$\mathrm{V}_{\text {min }}=$ minimum voltage limit

$\mathrm{P}_{\text {loss }}=$ the maximum power loss between bus $\mathrm{i}$ and the buses which have connections with bus number $\mathrm{i}$

$\mathrm{C}_{\mathrm{p}}=$ constant

To obtain the sensitive node, a third interval function is obtained to combine the above two interval functions of the voltage sensitivity and power loss. This third function is defined as follows:

$$
f_{t}(i)=f_{v}(i) * f_{p}(i)
$$

A lower value of $f_{t}$ (i) reflects a higher priority of bus i to be compensated. However, the interval outcomes of $\mathrm{ft}$ (i) must be sequentially ordered to determine the minimum value among them. Comparisons between intervals are more complicated than those of single numbers [18]. There are 18 meaningful relations between intervals. It is unclear even how to name all these comparison [18]. Ref. 19 refers to "certainly relations" and " possibly relations". If $\mathrm{X} 1$ and $\mathrm{X} 2$ are two interval numbers, it is to say that $\mathrm{X} 1$ is "certainly equal" to $\mathrm{X} 2$ if $\mathrm{X} 1$ and $\mathrm{X} 2$ are the same point; $\mathrm{X} 1$ is "possibly equal" to $\mathrm{X} 2$ if $\mathrm{X} 1$ and X2 overlap; and X1 and X2 are equals as sets if they are the same intervals. (Similarly, you have "possibly not equal", "certainly not equal" and "not equal as sets", 
etc.) [19]. In other words, it is difficult to order the interval numbers due to the overlapping between them [18].

To over come this complexity, several techniques are used to order the interval numbers such as ordering according to the lower or upper bounds of the interval numbers; the radius of the interval number ; or according to the midpoint of the interval numbers. Each of these methods is used according to the aim of ordering. i.e., if interval outcomes are compared according to their sharpness in bounds, the preferred technique of comparison is the radius comparison [19] which is the method of comparison selected here. All the interval outcomes of $f_{t}(i)$ are ordered according to their midpoint values. Then, the bus corresponding to the minimum value among the midpoint outcomes of $f_{t}$ (i) is the one first selected for compensation.

\section{The Proposed Algorithm}

The implementation of the proposed optimal capacitor sizing and placement technique in interval mathematics is performed in the Matlab ${ }^{\circledR}$ environment. The steps of the algorithm are summarized as follows:

1) Let the real and reactive load and the initial values for voltage magnitude and phase angle at each bus as an interval numbers with a realistic tolerance percentage of their single point estimate.

2) Perform the load flow program for the original uncompensated feeder to obtain the interval voltages at each bus using the interval backward/ forward sweep method.

3) Assume an initial value for the single point estimate capacitor cost $K_{c k}$ as the average cost for all available standards for the studied feeder.

4) Let the input parameters $\left(\mathrm{K}_{\mathrm{p}}, \mathrm{K}_{\mathrm{e}}, \mathrm{K}_{\mathrm{ck}}\right.$ and $\left.\mathrm{L}_{\mathrm{f}}\right)$ be interval numbers with a realistic tolerance of their single point estimates.

5) Obtain the interval distribution functions $f_{t}, f_{p}, f_{v}$.

6) Identify the sensitive bus that has the lowest value of the interval function $f_{t}$, [define here as the bus with the lowest mid point in the interval function $\mathrm{f}_{\mathrm{t}}$ ].

7) Compute the interval capacitor size $\left(\mathrm{Q}_{\mathrm{C}}\right)$, the interval current capacitor, the interval maximum saving $(\Delta S)$ and the corresponding interval loss reduction respectively at the chosen bus $(\Delta \mathrm{P})$.

8) Determine all the standard capacitor sizes $\left(\mathrm{Q}_{\mathrm{Cst}}\right)$ lying within the interval capacitor size at this bus. In case no standard size lies within the interval, then the one nearest to the interval is selected (i.e. the closest standard size to both the lower upper bounds of the interval). These procedures are applied at any one sensitive bus selected.

9) Perform the interval load flow calculations, for every single standard capacitor selected earlier, to ensure that no voltage violation takes place. If there is a voltage violation for one or more standard capacitor sizes, eliminate them from further consideration. If all the capacitor sizes result in voltage violation, then go to step 6 to select the next sensitive bus. 
10) If there is no voltage violation, set the standard capacitor size, among the series of standard sizes in this interval, that provides the highest voltage improvement at this bus provided that the evaluated interval maximum saving, the corresponding interval loss reduction and the interval capacitor size are positive.

11) Repeat steps 5-10 to get the next capacitor bus and hence the sequence of buses to be compensated until it is found that there is no significant voltage improvement can be achieved by further capacitor placement.

\section{Simulation results}

\section{The first feeder:}

To illustrate the numerical algorithm presented above, a test feeder whose load and feeder data are listed in [20] was investigated. The radial distribution feeder has 9 load buses and its rated substation voltage is $23 \mathrm{kV}$. The estimated values for $\mathrm{K}_{\mathrm{p}}, \mathrm{K}_{\mathrm{e}}$ and $\mathrm{L}_{\mathrm{f}}$ are $\$ 168 / \mathrm{kW}, \$ 0.3 / \mathrm{kWh}$, and 0.5 respectively [3]. Commercially available capacitor sizes with $\$ / \mathrm{kVAr}$ are used in the analysis. As the maximum capacitor size $\mathrm{Q}_{\mathrm{Cmax}}$ should not exceed the reactive load (i.e. 4186kVAr), this results in 27 possible capacitor sizes with their corresponding cost/kVAr and their values may be derived assuming a life expectancy of ten years (placement, maintenance, and running costs are neglected) [4].

Applying load flow solution on this feeder, before compensation, the cost function and the total power losses are $\$ 131,675$ and $783.8 \mathrm{~kW}$ respectively. The maximum and minimum interval bus voltage magnitudes are [0.9920, 0.9938] and [0.8233, 0.8516] p.u., where the interval voltage of the substation (bus number 0) is assumed to be [1.00, $1.00]$ p.u., thus we have generally $[0.8233,0.8516] \leq \mathrm{Vi} \leq[1.00,1.00]$ p.u.

The following sections describe the compensation procedure for the test feeder; with the input parameters $\mathrm{K}_{\mathrm{p}}, \mathrm{K}_{\mathrm{e}}, \mathrm{K}_{\mathrm{ck}}$ and $\mathrm{L}_{\mathrm{f}}$ as well as the bus load demand are all assumed to be represented as interval numbers with a prespecified tolerance. The computations are carried out using the Intlab toolbox [21].

The interval functions suggested $\left(f_{v}, f_{p}, f_{t}\right)$ are only used to identify the buses to be compensated according to the value of $f_{t}$. Then the value of the interval capacitor size, interval maximum saving and the corresponding interval loss reduction are computed using the governing equations given in [3-4]. Figure (1) shows the relation between the upper and the lower limits of the interval outcome of the interval function $f_{v}$ versus the midpoint of the interval voltage of the buses. 


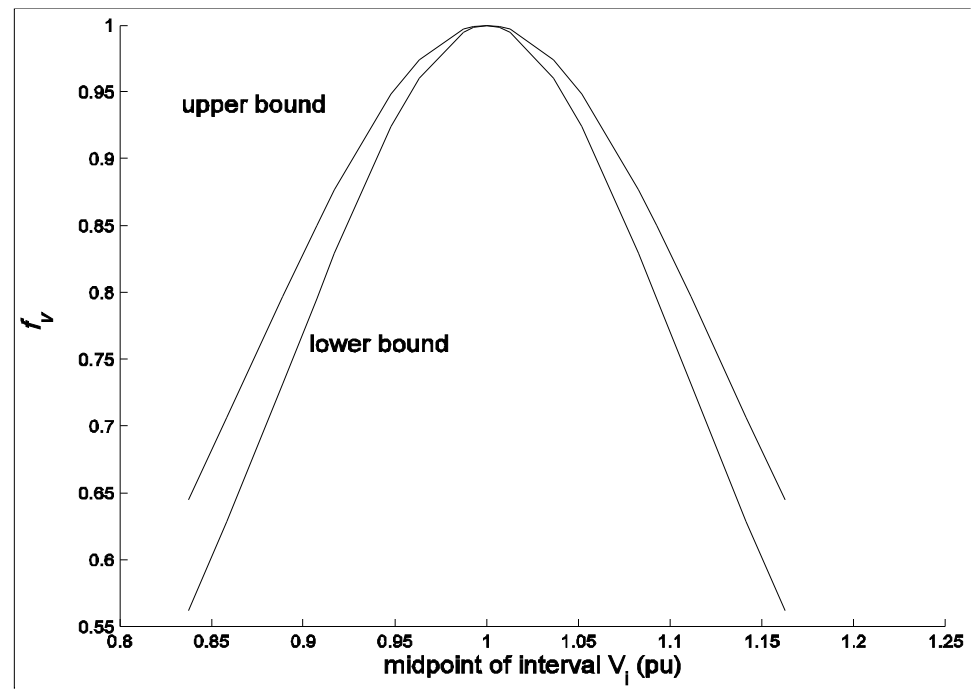

Figure (1): Interval function $f_{v}$ for voltage sensitivity

Table 1 describes the interval outcomes of $f_{t}$ at each node and their midpoint for a single located capacitor. It shows that bus 9 is the bus corresponding to the minimum value of the midpoint outcomes of $f_{t}$ (i), so it is the one which highly require, first, the reactive compensation by capacitor. After installing capacitor at this node, repeating the generation for the interval functions, it is observed that the next buses to be compensated are bus 5 and bus 3 respectively.

Table 2 shows the results obtained by the present method for different uncertainty levels in order to assess the uncertainties associated with the various input parameters $K_{P}, K_{e}$, $\mathrm{K}_{\mathrm{ck}}$ and $\mathrm{L}_{\mathrm{f}}$. The level of uncertainty of all parameters has been taken as $5 \%$ and $10 \%$. The table shows that the compensated nodes remain the same in all cases but it has been changed from the traditional method used in ref. 3, and ref. 4. For example at tolerance $5 \%$, the nodes became 9,5 and 3 rather than 5, 9 and 4. Also, the standard capacitor ratings has been changed using the new technique into 900, 1800 and 1350KVAr respectively for the corresponding nodes instead of 2700,450 and $750 \mathrm{KVAr}$ respectively for the corresponding nodes obtained from the traditional method. This new capacitor ratings lead to an improvement in the voltage profile from [0.8684, 0.8966] $\leq \mathrm{Vi} \leq[1.0,1.0] \mathrm{p} . \mathrm{u}$ (using the traditional technique $[3,4]$ ) into $[0.8734,0.9016] \leq \mathrm{Vi} \leq$ $[1.0,1.0]$ p.u (using the new technique).

It is observed that the interval bounds of $\Delta \mathrm{P}$ and $\Delta \mathrm{S}$ for the higher tolerances contains those of lower tolerances, e.g., the interval outcome of $\Delta \mathrm{S}$ for a $5 \%$ uncertainty is contained within the interval of the $10 \%$ level. It is also noted that increasing the uncertainty level into $10 \%$ leads to the improvement in voltage profile into [0.8758, $0.9059] \leq \mathrm{Vi} \leq[1.0,1.0]$ p.u. This occurs due to the changing in the standard capacitor sizes used in each tolerance level. Finally, the table shows, that as the interval outcome width increases (e.g. for 5\% and 10\% tolerances), the number of standard capacitor sizes available, for use by utilities, increases at all compensated nodes. 
Table (1): Results for interval outcomes of $f_{t}$ at each node

\begin{tabular}{|c|c|c|}
\hline $\begin{array}{c}\text { Node } \\
\text { no. }\end{array}$ & $\boldsymbol{f}_{\boldsymbol{t}}$ & Midpoint of $\boldsymbol{f}_{\boldsymbol{t}}$ \\
\hline 0 & {$[1.0000$,} & 1 \\
& $1.0000]$ & \\
\hline 1 & {$[0.9828$,} & 0.98312 \\
& $0.9835]$ & \\
\hline 2 & {$[0.9776$,} & 0.97884 \\
& $0.9801]$ & \\
\hline 3 & {$[0.9327$,} & 0.93957 \\
& $0.9464]$ & \\
\hline 4 & {$[0.9149$,} & 0.92699 \\
& $0.9391]$ & \\
\hline 5 & {$[0.8156$,} & 0.83893 \\
& $0.8622]$ & \\
\hline 6 & {$[0.7918$,} & 0.81905 \\
& $0.8463]$ & \\
\hline 7 & {$[0.7285$,} & 0.76098 \\
& $0.7934]$ & \\
\hline 8 & {$[0.6252$,} & 0.66411 \\
& $0.7030]$ & \\
\hline 9 & {$[0.5603$,} & 0.60193 \\
& $0.6435]$ & \\
\hline
\end{tabular}

Table (2): Results for different uncertainty levels

\begin{tabular}{|l|c|c|c|c|c|}
\hline $\begin{array}{c}\text { Uncertainty } \\
\text { level }\end{array}$ & $\begin{array}{c}\text { Node } \\
\mathbf{N o .}\end{array}$ & $\begin{array}{c}\mathbf{Q}_{\mathbf{C}} \\
\mathbf{k V A r}\end{array}$ & $\begin{array}{c}\mathbf{Q}_{\text {Cst }} \\
\mathbf{k V A r}\end{array}$ & $\begin{array}{c}\Delta \mathbf{P} \\
(\mathbf{k W})\end{array}$ & $\begin{array}{c}\Delta \mathbf{S} \\
\mathbf{( \$ )}\end{array}$ \\
\hline \multirow{3}{*}{$5 \%$} & 9 & {$[836,1026]$} & 900 & {$[32,49]$} & {$[5558,7553]$} \\
\cline { 2 - 6 } & 5 & {$[1535,1893]$} & 1800 & {$[20,30]$} & {$[3275,4506]$} \\
\cline { 2 - 6 } & 3 & {$[1128,1458]$} & 1350 & {$[3.8,5.9]$} & {$[395,597]$} \\
\cline { 2 - 6 } & Total & & & {$[\mathbf{5 5 . 8 , 8 5}]$} & {$[\mathbf{9 2 2 8 , 1 2 6 5 6}]$} \\
\hline \multirow{3}{*}{$10 \%$} & 9 & {$[755,1136]$} & 1050 & {$[25,58]$} & {$[4744,8773]$} \\
\cline { 2 - 6 } & 5 & {$[1267,1933]$} & 1800 & {$[13.5,31]$} & {$[2330,4436.4]$} \\
\cline { 2 - 6 } & 3 & {$[868.9,1476]$} & 1350 & {$[2.8,6.8]$} & {$[245,578.6]$} \\
\cline { 2 - 6 } & Total & & & {$[\mathbf{4 1 . 3 , 9 6}]$} & {$[\mathbf{7 3 1 9 , 1 3 7 8 8}]$} \\
\hline
\end{tabular}




\section{The second feeder:}

The test distribution feeder is an $11 \mathrm{kV}$ overhead line, named KAHA2, fed from the KANATER distribution network which is part of the Cairo Electricity Distribution Company (CEDC). The feeder consists of 22 nodes and the data of this feeder are given in [22]. The power factor is assumed to be 0.82. Applying load flow before compensation, the maximum and minimum interval bus voltage magnitudes are [0.971, 0.9801] and [0.873, 0.913] p.u., where the interval voltage of the substation (bus number 0$)$ is assumed to be $[1.00,1.00]$ p.u., thus we have generally $[0.873,0.913] \leq \mathrm{Vi}$ $\leq[1.00,1.00]$ p.u.

Table 3 shows that only two compensated capacitors are installed. This may be due the fact that the feeder is, relatively, not heavily loaded and that the voltage profile is generally good. In the case of 5\% uncertainty, the two compensated nodes are 14 and 6. This leads to an improvement in the voltage profile to be $[0.9432,0.9832] \leq \mathrm{V}_{\mathrm{i}} \leq[1.0$, 1.0] p.u. The table also shows that in the case of $10 \%$ uncertainty, the compensated nodes remain two but changed into nodes 14 and 5 .

It is observed that the interval bounds of $\Delta \mathrm{P}$ and $\Delta \mathrm{S}$ for the higher tolerances contains those of lower tolerances, e.g., the interval outcome of $\Delta S$ for a $5 \%$ uncertainty is contained within the interval of the $10 \%$ level. It is also noted that when the uncertainty level was increased to $10 \%$, the improvement in voltage profile becomes [0.9458, $0.9858] \leq \mathrm{V}_{\mathrm{i}} \leq[1.0,1.0]$ p.u. This may be attributed to the changing in the standard capacitor sizes used for each tolerance level.

Table (3): Results for different uncertainty levels

\begin{tabular}{|c|c|c|c|c|c|}
\hline $\begin{array}{c}\text { Uncertainty } \\
\text { level }\end{array}$ & $\begin{array}{c}\text { Node } \\
\text { No. }\end{array}$ & $\begin{array}{c}\mathbf{Q}_{\mathbf{C}} \\
\mathbf{k V A r}\end{array}$ & $\begin{array}{c}\mathbf{Q}_{\text {Cst }} \\
\mathbf{k V A r}\end{array}$ & $\begin{array}{c}\Delta \mathbf{P} \\
(\mathbf{k W})\end{array}$ & $\begin{array}{c}\Delta \mathbf{S} \\
\mathbf{( \$ )}\end{array}$ \\
\hline \multirow{4}{*}{$\mathbf{5 \%}$} & 14 & {$[1273,1561]$} & 1500 & {$[43,66]$} & {$[7493,10189]$} \\
\cline { 2 - 6 } & 6 & {$[258,327]$} & 300 & {$[1.1,1.7]$} & {$[138.6,201.5]$} \\
\cline { 2 - 6 } & Total & & & {$[\mathbf{4 4 . 1 , 6 7 . 7}]$} & {$[\mathbf{7 6 3 1 . 6 , 1 0 3 9 0 . 5}]$} \\
\hline \multirow{3}{*}{$\mathbf{1 0 \%}$} & 14 & {$[1149,1729]$} & 1650 & {$[34,78]$} & {$[6393,11840]$} \\
\cline { 2 - 6 } & 5 & {$[125,221]$} & 150 & {$[0.3,0.7]$} & {$[27,67]$} \\
\cline { 2 - 6 } & Total & & & {$[\mathbf{3 4 . 3 , 7 8 . 7}]$} & {$[\mathbf{6 4 2 0 , 1 1 9 0 7}]$} \\
\hline
\end{tabular}




\section{Conclusions:}

The uncertainties in the load demand and that associated with capacitor allocation in radial distribution feeders are integrated to get a realistic solution for capacitor placement problem. Modeling the uncertainties in the load demands is treated by solving the load flow in interval form using the backward/ forward sweep technique. The interval voltages obtained from load flow is used in the governing equations of the capacitor allocation solution. Interval distribution functions are introduced to order the sensitive nodes that require reactive compensation by capacitors. The interval capacitor size, interval maximum cost saving, and the corresponding interval loss reduction are determined using a combined heuristic and interval mathematic method. The effects of uncertain inputs are examined for different uncertainty levels. A significant improvement in the voltage profile is determined using the proposed technique. Implementation of the technique is demonstrated using two radial distribution feeders, one of which is a sample of the Cairo Electricity Distribution Company and acceptable results were achieved. 


\section{References:}

[1] K. Prakash, M. Sydulu, "Particle Swarm Optimization Based Capacitor Placement on Radial Distribution Systems," IEEE Power engineering society summer meeting, June 2007, 1-5.

[2] M. Haghifam, O. Malek, "Genetic algorithm-based approach for fixed and switchable capacitors placement in distribution systems with uncertainty and time varying loads," IET Generation Transmission and

[3] distribution, March 2007; 1(2), 244-252.

M. Abouelsaad, N. Abdel-Gawad, M. El Bahy, M. Abou El-Ata, I. El Shair, "Assessment of uncertainty in reactive power compensation

[4] analysis of distribution systems", Power Engineering, 2006 Large Engineering Systems Conf, Canada July 2006, 61-65.

M. Abouelsaad, N. Abdel-Gawad, M. El Bahy, M. Abou El-Ata, I. M. El

[5] Shair, "Capacitor allocation and sizing in distribution feeders using interval mathematics", Middle-East Power Systems Conf

[6] (MEPCON'2006), El-Minia University, Egypt, Dec. 19-21, 2006.

H. N. Ng, and M. M. A. Salama, "Fuzzy optimal capacitor sizing and

[7] placement," in Proc. Canadian Conf. Elect. Comput. Eng., vol. 2, pp. 680-683, 1995.

Biswarup Das, "Radial distribution system power flow using interval

[8] arithmetic," Elect Power and Energy Syst 2002; 24: 827-36.

L. V. Barboza, G. P. Dmuro, R. H. S. Reiser, "Towards interval analysis

[9] of the load uncertainty in power electric systems," 8th Int Conf on Probabilistic Methods Applied to Power Syst, Iowa State University,

[10] Ames, Iowa,,2004; Sept. 12-16.

L. V. Barboza, G. P. Dmuro, R. H. S. Reiser, "Power flow with load

[11] uncertainty," TEMA Tend. Mat. Apl. Comput 2004; 5 (1): 27-36.

Z. Wang, F. Alverado," Interval arithmetic in power flow analysis," IEEE

[12] Trans on Power Syst 1992; 7(3): 1341-9.

H. Shaalan, "Modeling uncertainty in electric utility economics using

[13] interval mathematics," in Proc. of the 4th IASTED Int Conference on Power \& Energy Syst Spain ; 2000: 675-8.

[14] H. Sun, D.C. Yu, Y. Xie, "Application of fuzzy set theory to power flow analysis with uncertain power injections," IEEE Power Eng Society,

[15] winter meeting 2000; 2: 1191-6.

Pei Zhang, Stephen T. Lee, "Probabilistic load flow computation using

[16] the method of combined cumulants and gram-charlier expansion," IEEE Trans on Power Syst 2004; 19 (1):.676-82. 
[17] P. Zhang, S.T. Lee, "A new computation method for probabilistic load flow study," in Proc. of the Power Con Int Conf on Power Syst Tech, 2002; 4, 2038-42.

[18] B. Baran, E. A. Martinez, T. A. Diverio, "Solving electrical power load flow problems using intervals", 2002 SIAM Workshop on Validated Computing. Toronto, Canada,2002 .

[19] G.I. Hargreaves," Interval analysis in MATLAB", Numerical Analysis Report, no. 416, Manchester Centre for Computational Mathematics, [20] 2002.

CS. Cheng, D. Shirmohammadi," A three phase power flow method for

[21] real time distribution system analysis", IEEE Trans Power Syst 1995; 10 (2), 671-9.

S. A. Soliman, H. K. Temraz, M. E. El-Hawary, "Fuzzy systems

[22] applications to reactive power compensation in primary distribution feeders,"IEEE Power engineering society summer meeting, July 2001; 3, 1597-609.

[23] Brian Hayes," A lucid interval," American Scientist 2003; 91(6): 484-8. D. Chiriaev, G. Walster, "Interval arithmetic specification," 1999; www.mscs.mu.edu / ̃lobsol / walster-papers.html.

[24] J. J. Grainger, S. H. Lee, "Optimal size and location of shunt capacitor for reduction of losses in distribution feeders", IEEE Trans. Power App.

[25] Syst 1981; 3: 1105-18.

S. M. Rump, Intlab-Interval Laboratory, Developments in Reliable Computing, (T. Csendes, ed.), Kluwer, Boston, 1990; 77-104.

E. Hassouna, E. Mohamed, A. Amer, M. Swidan, "Optimal capacitor allocation on radial feeders using genetic algorithm," Sixth Middle East Power Systems Conference (MEPCON'98), Mansoura, Egypt, pp. 82-87, December 15-17, 1998. 